\title{
Economic Burden and Health-Related Quality of Life Associated with Current Treatments for Anaemia in Patients with CKD not on Dialysis: A Systematic Review
}

\author{
Pablo E. Pergola ${ }^{1} \cdot$ Roberto Pecoits-Filho ${ }^{2,3} \cdot$ Wolfgang C. Winkelmayer ${ }^{4} \cdot$ Bruce Spinowitz $^{5} \cdot$ Samuel Rochette $^{6}$. \\ Philippe Thompson-Leduc ${ }^{6}$ (D) Patrick Lefebvre ${ }^{6} \cdot$ Gigi Shafai $^{7} \cdot$ Ana Bozas $^{7} \cdot$ Myrlene Sanon $^{8} \cdot$ Holly B. Krasa ${ }^{8}$
}

Published online: 9 April 2019

(C) The Author(s) 2019

\begin{abstract}
Background The cost and health-related quality of life (HRQoL) burden associated with treatments for anaemia of chronic kidney disease (CKD) is not well characterized among non-dialysis-dependent (NDD) patients.

Objective Our objective was to review the literature on costs and HRQoL associated with current treatments for anaemia of CKD among NDD patients.

Methods The Cochrane Library, MEDLINE, Embase, NHS EED, and NHS HTA databases were searched for original studies published in English between 1 January 2000 and 17 March 2017. The following inclusion criteria were applied: adult population; primary focus was anaemia of CKD; patients received iron supplementation, red blood cell transfusion, or erythropoiesis-stimulating agents (ESAs); and reported results on HRQoL and/or costs. Studies that included NDD patients, did not compare different treatments, and had relevant designs were retained. HRQoL and cost outcomes were summarized in a narrative synthesis.

Results In total, 16 studies met the inclusion criteria: six randomized controlled trials, four prospective single-arm trials, three retrospective studies, one prospective observational study, one simulation study, and one cross-sectional survey. All included ESAs. Treatment of anaemia (compared with no treatment) was associated with HRQoL improvements in five of six studies and lower costs in four of four studies. Treatment aiming for higher haemoglobin targets (compared with lower targets) resulted in modest HRQoL improvements, higher healthcare resource utilization (HRU), and higher costs.

Conclusions In NDD patients, untreated anaemia of CKD leads to higher costs, higher HRU, and lower HRQoL compared with initiating anaemia treatment. Relative to aiming for lower haemoglobin targets with ESAs, higher targets conferred modest HRQoL improvements and were associated with higher HRU.
\end{abstract}

Philippe Thompson-Leduc

philippe.thompson-leduc@analysisgroup.com

Renal Associates PA, San Antonio, TX, USA

2 George Institute for Global Health, Newtown, NSW, Australia

3 School of Medicine Pontificia, Universidade Catolica do Parana, Curitiba, PR, Brazil

4 Baylor College of Medicine, Houston, TX, USA

5 NewYork-Presbyterian Queens, Queens, NY, USA

6 Analysis Group, Inc., 1190 Avenue Des Canadiens-de-Montréal, Tour Deloitte, Suite 1500, Montreal, QC H3B 0G7, Canada

7 Akebia Therapeutics, Cambridge, MA, USA

8 Otsuka Pharmaceutical Development and Commercialization, Rockville, MD, USA

\section{Key Points for Decision Makers}

In this literature review, non-treatment of patients with anaemia of chronic kidney disease (CKD) who were not on dialysis resulted in higher costs and was associated with poorer health-related quality of life (HRQoL), which emphasizes the need for treatment.

However, aiming for haemoglobin targets $>12 \mathrm{~g} / \mathrm{dL}$ led to seemingly modest HRQoL improvements of uncertain clinical significance. Improvements in the vitality domain appeared more robust than those in other domains.

Effective treatment options with improved safety profiles are needed to improve the HRQoL of these patients with anaemia of CKD. 


\section{Introduction}

Chronic kidney disease (CKD) is defined by the 2012 Kidney Disease: Improving Global Outcomes (KDIGO) guidelines as "abnormalities of kidney structure or function, present for $>3$ months, with implications for health" [1]. With a prevalence of $3-18 \%$ globally [2], CKD is an important public health problem associated with high rates of mortality and disability. The disease is caused by the progressive loss of kidney function and consequential accumulation of uremic toxins, which can ultimately lead to the requirement for kidney-replacement therapy (KRT; i.e. dialysis or kidney transplant), generally when glomerular filtration rate falls below $15 \mathrm{mg} / \mathrm{dL}[1,3,4]$. There are few therapies that can reverse disease progression, and 3-year survival following diagnosis of end-stage renal disease (ESRD) is only $57 \%$ and $68 \%$ among haemodialysis and peritoneal dialysis patients, respectively [5]. Kidney transplantation, the preferred treatment for patients with ESRD, involves a long wait or is not always an option: in 2015 in the USA, 99,120 patients were waiting for kidney transplants, yet only 18,805 kidney transplants were performed in the USA in that year. The median wait time for an individual's first kidney transplant is 3.9 years [6]. Therefore, the proactive treatment and preservation of kidney function are of utmost importance in pre-dialysis patients.

The cost and health-related quality of life (HRQoL) burden of patients with non-dialysis-dependent (NDD) CKD increase substantially with disease progression while maintaining better overall HRQoL [7-9] and incurring lower costs [10] than dialysis-dependent (DD) patients. In the USA, the prevalence of CKD stage 1-4 is estimated at 30 million individuals and that of patients with DD-CKD at 500,000 . As many as $70 \%$ of affected individuals could be undiagnosed and remain in primary care [11]. In the USA in 2012, the average Medicare-insured patient with stage 1-2 CKD incurred annual healthcare costs estimated at \$US17,969, and those with CKD stage 3 incurred costs of $\$$ US19,392 [12]. Among privately insured patients, annual costs are estimated to be approximately $\$$ US10,000-12,000 per patient [8]. Due to the high number of patients affected and the associated costs, NDD-CKD imposes a heavy burden on healthcare systems.

Diagnosis of CKD may be prompted by patient-reported fatigue (or other symptoms) caused by anaemia, which is a significant contributor to the burden of CKD. Other patient-reported symptoms such as reduced mental activity, insomnia, and reduced libido have also been attributed to anaemia and contribute to reducing the quality of life of this patient population in CKD [13-18]. Anaemia affects $8.4 \%$ of patients with CKD stage 1, increasing to $53.4 \%$ for patients with CKD stage 5 [19]. Current therapies for anaemia of CKD include iron replacement, erythropoiesisstimulating agents (ESAs), and/or red blood cell transfusions (RBCTs), the latter being used almost always as a rescue therapy. In NDD patients not on iron or ESA therapy, a trial of intravenous iron is recommended by current guidelines [20]. Furthermore, ESAs are not recommended in this population unless haemoglobin levels fall below a threshold of $10.0 \mathrm{~g} / \mathrm{dL}$ [20]. The clinical utility of ESAs is dependent on balancing their efficacy with the concerns of increased risks of major adverse cardiovascular events (MACE) [20-24], and the fact that nearly $10 \%$ of patients are ESA-hyporesponsive. Their prohibitive cost forms an additional barrier that hinders access to this treatment class for many patients. Therefore, for a large number of patients with NDD-CKD, treatment with ESAs is ineffective, insufficient, inaccessible, or contraindicated as the benefits of ESAs do not outweigh their potential risks.

Based on these limitations, clinical practice guidelines, as well as US and European regulatory agencies, usually recommend against intentionally aiming for haemoglobin treatment targets above $11.5 \mathrm{~g} / \mathrm{dl}$ and discourage exceeding the $13 \mathrm{~g} / \mathrm{dL}$ threshold with ESAs in NDD- and DD-CKD [20, 25-28]. This relatively recent recommendation included in updated guidelines caused a reduction in the proportion of patients with NDD-CKD using ESAs from 2009 to 2013 [29, 30]. Regional disparities in the real-world clinical management of anaemia of CKD do exist, as exemplified by the fact that higher haemoglobin levels are achieved by real-world patients in regions such as Japan, Brazil, and Europe relative to patients in the USA [31]. Thus, having an updated global assessment of the outcomes related to the treatment of anaemia of CKD is warranted.

Four systematic literature reviews (SLRs) published between 2010 and 2017 reviewed the cost burden and/or HRQoL of anaemia of CKD [32-35]. However, three of them were restricted to specific geographic areas or did not focus on patients with NDD-CKD [32, 33, 35], and the fourth studied the impact of ESAs on HRQoL based only on data from prospective randomized trials that included DD patients [34]. The 2010 review by van Nooten et al. [33] concluded that the evidence on the economic and HRQoL burden in NDD-CKD is limited but nonetheless substantial. Because randomized controlled trials (RCTs) are conducted in highly controlled settings that may significantly differ from real-world clinical practice, the applicability of RCT findings to the real world could be limited. In addition, periodically reassessing the economic value of treating anaemia of CKD is necessary, as evidenced by the drastic change in epoetin alfa's cost effectiveness from 1990 to 2000 [36]. Therefore, to provide an updated and global perspective on the economic burden and HRQoL outcomes of anaemia of $\mathrm{CKD}$, we conducted a systematic review of the literature 
on the costs and HRQoL associated with current treatments for anaemia of CKD among patients with NDD-CKD and included real-world studies in addition to RCTs.

\section{Methods}

\subsection{Data Source}

Electronic databases, including the Cochrane Library, MEDLINE (including MEDLINE In-Process), Embase, National Institute for Health Research Economic Evaluation Database (NHS EED), and National Institute for Health Research-Health Technology Assessment (NHS HTA), were searched on 17 March 2017 to identify relevant publications in English.

\subsection{Literature Search Strategy and Study Selection Process}

Studies were required to meet the following criteria: adult population (i.e. at least one patient aged $\geq 18$ years); disease area was anaemia of CKD; iron/ferric supplementation, RBCT, or ESAs (i.e. epoetin or darbepoetin) were among the included treatments; study population was NDD (or, if both DD and NDD patients were included, outcomes were presented separately for NDD patients); and costs and/or HRQoL were among the outcomes investigated (Appendix 1).

Cost outcomes included healthcare resource utilization (HRU), direct costs, and indirect costs. An HRU outcome corresponded to any measurement of the healthcare resources used by patients, which included medical visits (inpatient and outpatient) and use of rescue therapies (e.g. RBCT). Direct costs corresponded to costs paid by payers or to patients' out-of-pocket costs, such as drug costs or medical visits. Indirect costs corresponded to costs ensuing from a patient's inability to perform normal daily activities, such as work (i.e. loss of productivity costs).

Exclusion criteria included strictly paediatric population (i.e. all patients aged $<18$ years); study population was non-human (i.e. animal or cell-based studies); publication was a letter, editorial, comment, case report, biography, or address (i.e. not a study in which new results were generated); article was not in English; article was published before 1 January 2000. Studies that did not allow for the evaluation of incremental cost or HRQoL outcomes from a particular treatment (i.e. head-to-head comparisons between different treatments, dose-escalation studies, treatment switch studies, programme evaluation studies, etc.) were also excluded. This is because the design of these studies could not help achieve the objective of the current study.
The study selection process was conducted in two steps (Fig. 1). First, titles and abstracts were screened by two independent reviewers (SR, L-AD [acknowledged], or FK-K [acknowledged]) for eligibility based on the aforementioned inclusion and exclusion criteria. Discrepancies in the decisions were resolved through discussion, and a third reviewer (PT-L) was consulted whenever consensus was not reached. Second, two independent reviewers (SR, L-AD, or FK-K) reviewed the full texts of studies retained in the prior step to determine their eligibility based on the same aforementioned eligibility criteria. Disagreements in decisions were resolved through discussion. When consensus was not reached, a third independent reviewer (PT-L) was consulted.

\subsection{Data Extraction}

Two independent reviewers (from MarksMan Healthcare Solutions LLP) extracted data from the full publications. Discrepancies were resolved through discussion. Contingent on availability, select variables were extracted from the included publications and recorded in an Excel spreadsheet (Appendix 2).

\subsection{Analysis}

Because study designs and outcomes were anticipated to be heterogeneous, a meta-analysis was not expected to be feasible; thus, results were summarized in a narrative synthesis. Although the clinical significance of HRQoL findings was often not assessed using minimal clinically meaningful differences (MCIDs), results were compared with MCID thresholds found in the literature (Appendix 3). Costs and cost differences were extracted as reported without currency standardization or adjustment for inflation.

\section{Results}

\subsection{Search Results}

In total, 1625 unique publications were retrieved from the electronic search strategy. After screening by titles and abstracts, 418 (25.7\%) full-length publications were assessed for eligibility. Of these, 30 (7.2\%) met inclusion criteria. After eliminating studies that did not allow for the evaluation of incremental cost or HRQoL outcomes from a particular treatment, 16 (53.3\%) were included in the current analysis (Fig. 1). Most studies (12 of 16 [75.0\%]) were based on data collected before 2011 [16, 23, 37-46]. 


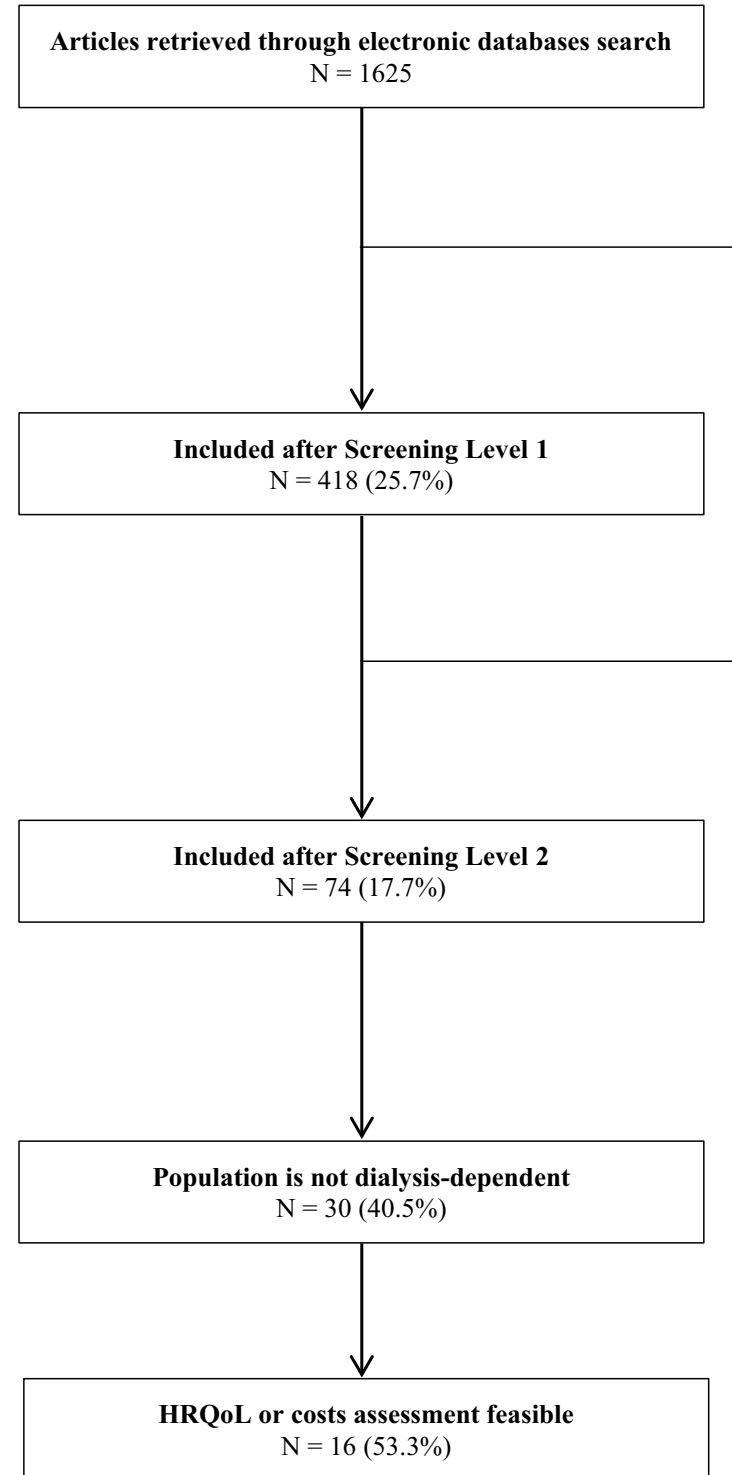

Articles rejected during Screening Level 1 (based on titles and abstracts) 1207

Article did not focus on anemia

Article did not mention chronic kidney disease

Article did not include an outcome of interest

Article did not include an intervention of interest

Article did not focus on human populations

Article included pediatric patients only

Design of the study was not eligible

Article is a duplicate

Article was not in English

Article was published prior to 2000

Other

$\begin{array}{ll}\text { Articles rejected during Screening Level } 2 \text { (based on full-length texts) } & \mathbf{3 4 4} \\ \text { Article did not include an outcome of interest } & 163 \\ \text { Article is not presenting original data (review) } & 49 \\ \text { Anemia of CKD is not the focus of the article } & 38 \\ \text { Article did not mention chronic kidney disease } & 32 \\ \text { Article did not focus on anemia } & 22 \\ \text { Article did not include an intervention of interest } & 21 \\ \text { Article did not focus on human populations } & 5 \\ \text { Design of the study was not eligible } & 5 \\ \text { Article is a duplicate } & 3 \\ \text { Article was not in English } & 3 \\ \text { Article included pediatric patients only } & 2 \\ \text { Full-length text was not found } & 1 \\ \text { Article was published prior to } 2000 & 0 \\ \text { Other } & 0\end{array}$

Fig. 1 The PRISMA statement flow diagram. $C K D$ chronic kidney disease, $H R Q o L$ health-related quality of life

\subsection{Study Designs and Outcomes}

Six (37.5\%) RCTs [23, 37, 40, 47-49], four (25.0\%) prospective single-arm trials $[38,44-46]$, three $(18.8 \%)$ retrospective studies [41-43], one (6.3\%) prospective observational study [16], one (6.3\%) simulation study [39], and one (6.3\%) cross-sectional survey [14] were included (Fig. 2). Included studies comprised four $(25.0 \%)$ real-world studies [16, 41-43], none of which had data collected prior to 2011. Cost outcomes were reported in three (18.8\%) articles [41-43], HRQoL outcomes were reported in ten $(62.5 \%)$ articles [14, 16, 37, 38, 40, 44, 45, 47-49], and both costs and HRQoL outcomes were reported in three (18.8\%) articles (Table 1) $[23,39,46]$.

\subsection{Interventions and Haemoglobin Targets}

ESA treatment was the intervention of interest in all included studies, including those with concomitant iron supplementation. No studies investigated RBCT (Table 1). Haemoglobin targets ranged between 9.0 and $10.9 \mathrm{~g} / \mathrm{dL}$ [39] and $13.0-15.0 \mathrm{~g} / \mathrm{dL}$ [49]. Five studies $(31.3 \%)$ did not specify a haemoglobin target $[14,16,38,41,43]$.

\subsection{Geography}

Studies were conducted across a range of geographical areas: six (37.5\%) studies in North America exclusively [16, 39, 41-43, 46], two (12.5\%) in Europe exclusively [14, 38 ], and eight $(50.0 \%)$ elsewhere (including international 


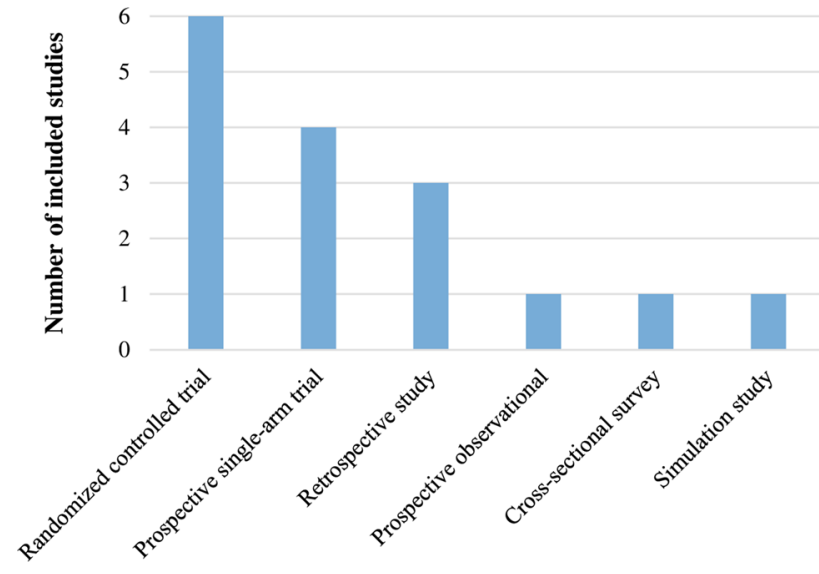

Fig. 2 Number of included studies by study design

collaborations; Table 1 and Fig. 3) [23, 37, 40, 44, 45, 47-49]. Five of the six (83.3\%) studies that reported on costs were conducted in North America [39, 41-43, 46]. Of the 13 studies that reported HRQoL outcomes, eight $(61.5 \%)$ were conducted elsewhere (including international collaborations) [23, 37, 40, 44, 45, 47-49], three (23.1\%) were conducted in North America $[16,39,46]$ and two $(15.4 \%)$ in Europe (Table 1) [14,38]. Among eight studies conducted in other or mixed locations, six (75.0\%) were RCTs. For the three (18.8\%) studies with data collected after 2011 [14, 47, 48], two were international collaborations $[47,48]$ and one was conducted in Europe [14].

\subsection{Health-Related Quality of Life (HRQoL) Measurements Used}

Among these 13 studies, the generic 36-Item Short-Form Survey (SF-36) was used in eight (61.5\%) [23, 37, 38, 40, 44, 47-49]; the Linear Analog Scale Assessment (LASA) [23, 46], Kidney Disease Questionnaire (KDQ) [23, 46], Kidney Disease Quality of Life (KDQoL) [14, 16], and Functional Assessment of Cancer Therapy (FACT)-Fatigue [47, 48], were each used in two (15.4\%); and quality-adjusted lifeyears (QALYs) [39], Functional Assessment of Chronic Illness Therapy (FACIT)-Fatigue [40], EuroQoL-5 Dimensions (EQ-5D) [47], and a customized approach [45] were each used in one study. While QALYs are not a measure of HRQoL, they were considered as such as they provide insight into the incremental gains in HRQoL associated with a particular treatment.

\subsection{Impact of Treatments on HRQoL}

Six studies with sample sizes ranging between 45 and 4038 patients compared HRQoL outcomes in ESA-treated versus ESA-untreated patients [14, 40, 45-48]. In two placebo-controlled RCTs, HRQoL was generally improved by ESAs, although there were discrepancies observed between the statistical significance and clinical significance (MCID) of the results (Table 2) [47, 48]. Two single-arm studies reported significant $\mathrm{HRQ}$ oL improvements after ESA initiation compared with baseline [45, 46], and that reported by Provenzano et al. [46] appeared clinically significant (i.e. MCID reached; Table 2). The study by Hirakata et al. [40] was an RCT designed to compare the impact of aiming for haemoglobin levels of $12-13 \mathrm{~g} / \mathrm{dL}$ (with darbepoetin alfa) versus levels of $10-12 \mathrm{~g} / \mathrm{dL}$ (with epoetin alfa). These levels were achieved after a 'dose-response' phase, during which patients in both cohorts achieved levels of $12 \mathrm{~g} / \mathrm{dL}$, and when HRQoL was assessed [40]. The authors reported clinically and statistically meaningful improvements in HRQoL during the maintenance phase relative to baseline (Table 2). In contrast, a cross-sectional study by Eriksson et al. [14] found that ESA-untreated patients had higher HRQoL than ESA-treated patients (Table 2).

Five studies with sample sizes ranging between 25 and 1432 compared HRQoL among patients with high versus low haemoglobin treatment targets [23, 37, 39, 44, 49]. Two studies with sample sizes ranging between 371 and 1186 assessed the HRQoL impact of having different haemoglobin levels [16, 38]. In two RCTs, 'vitality' (i.e. a domain measuring general energy/fatigue) was clinically and significantly higher in the high haemoglobin target group [37, 49], whereas other SF-36 domains showed marginal improvements of uncertain clinical significance (i.e. MCID often not reached; Table 2). In another RCT, Singh et al. [23] found non-significant improvements for patients randomized to achieve higher haemoglobin levels, except for the SF-36 domain 'emotional role'. Moreover, after 8 months of follow-up on ESA treatment that aimed to raise haematocrit levels to 36\%, Kawaguchi et al. [44] did not find significant differences in HRQoL relative to baseline (some patients may have been treated at baseline; Table 2). A cost-utility analysis conducted by Clement et al. [39] showed that gains in QALY relative to no treatment were smaller for haemoglobin targets of $11.0-12.0 \mathrm{~g} / \mathrm{dL}$ and $>12.0 \mathrm{~g} / \mathrm{dL}$ compared with a haemoglobin target of 9.0-10.9 g/dL (Table 2) [39]. Two studies reported that higher haemoglobin levels were generally associated with improved overall HRQoL $[16,38]$.

\subsection{Costs}

Four studies with sample sizes ranging between 152 and 37,105 investigated the costs of treated versus untreated anaemia of CKD [41-43, 46]. In a single-arm prospective study, Provenzano et al. [46] reported that the proportion of patients who required RBCT decreased from 11.1 to $3.7 \%$ after initiating ESA treatment (Table 3, Fig. 4). Using a retrospective cohort study design, Wish et al. [41] found that 


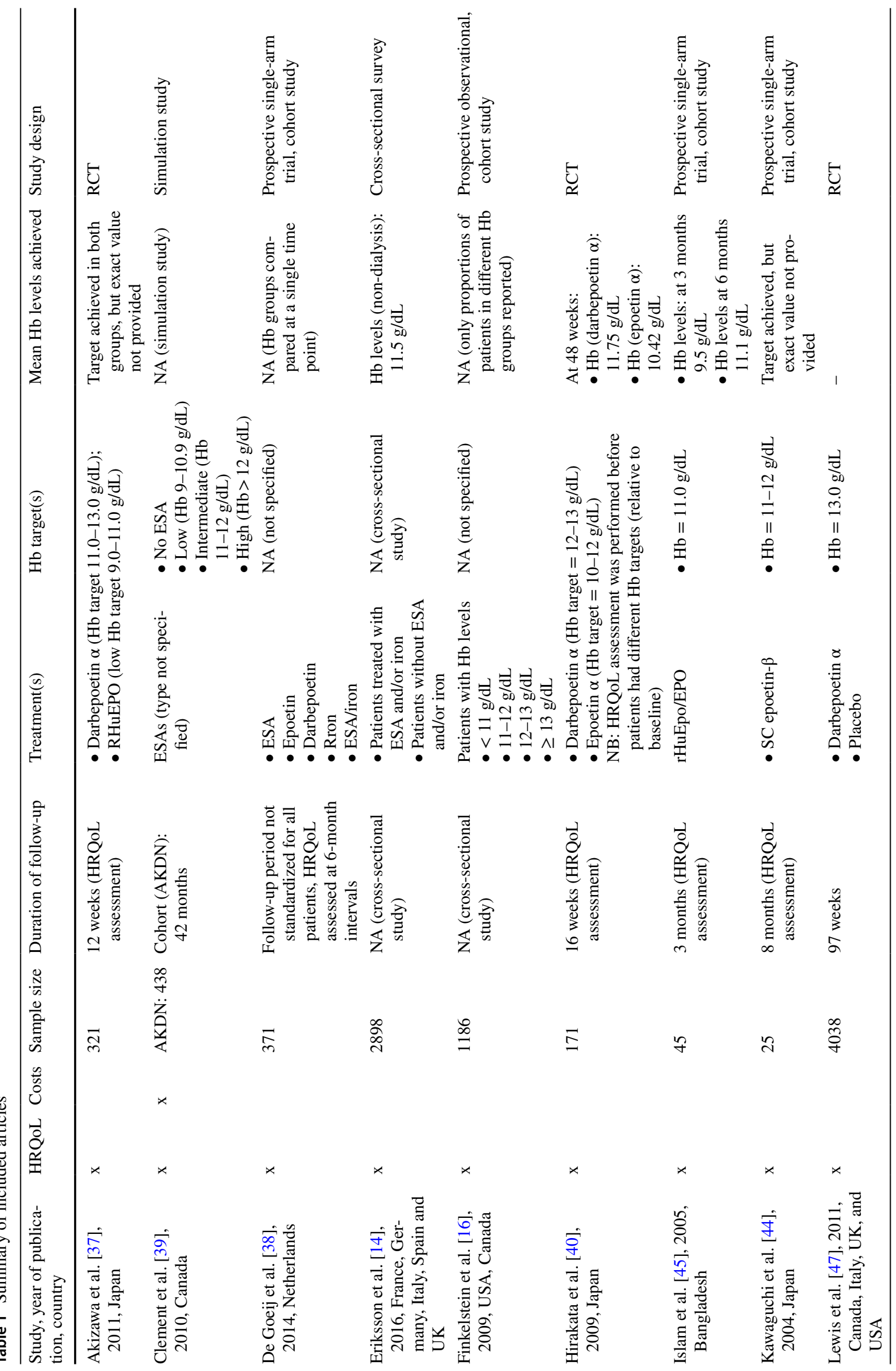




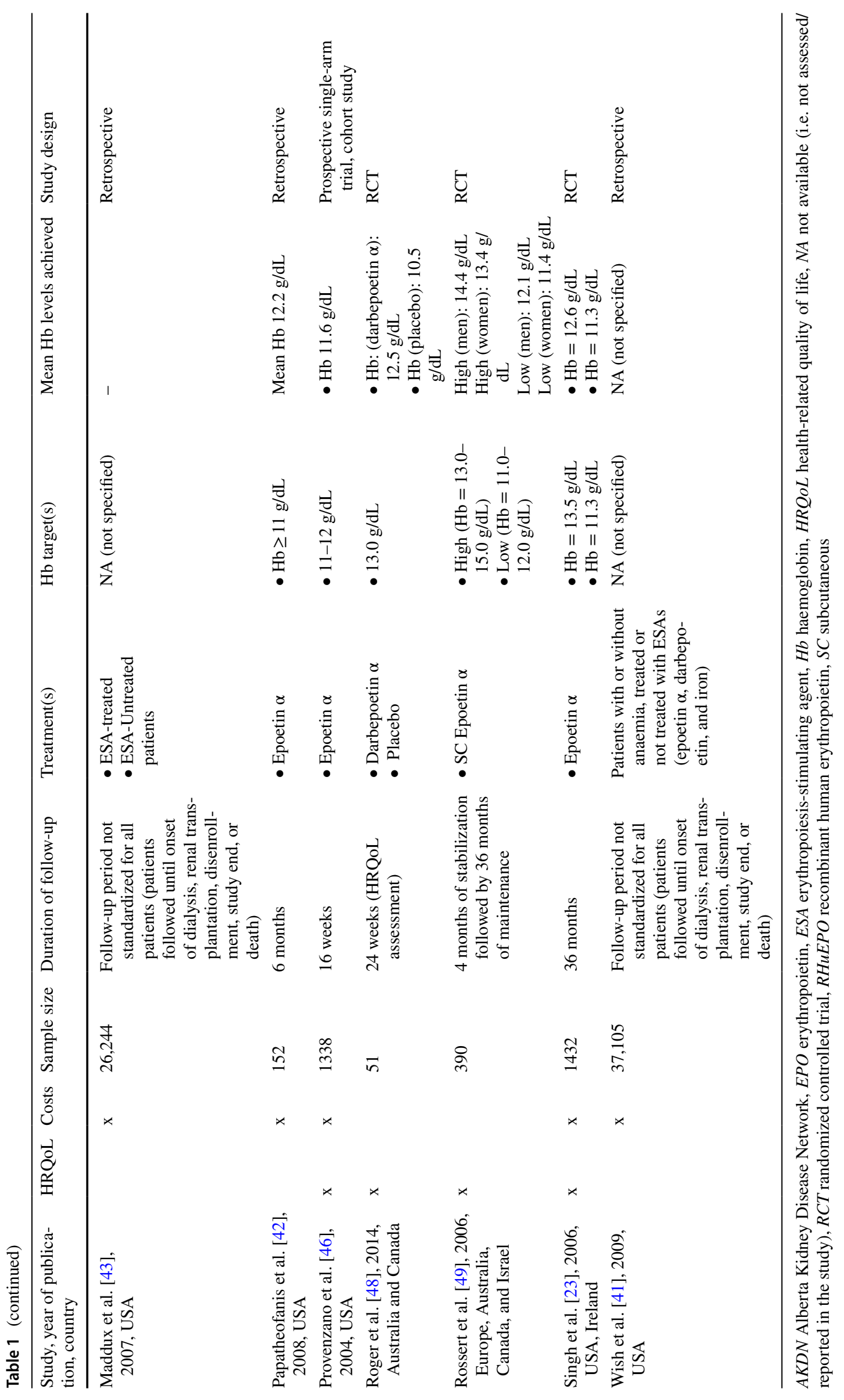




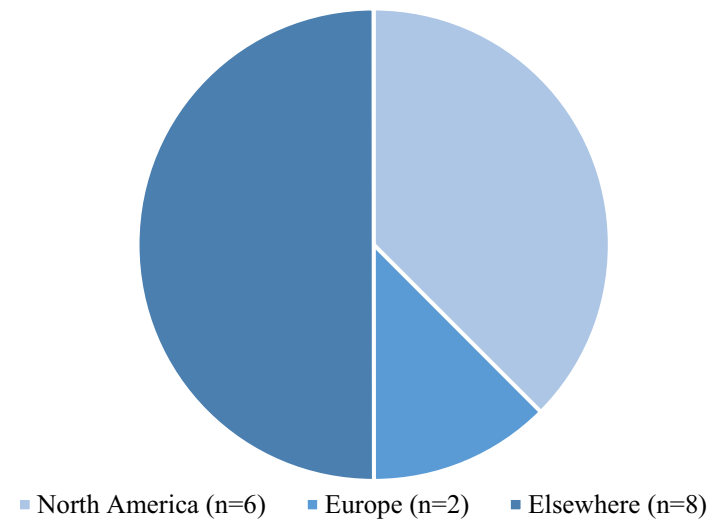

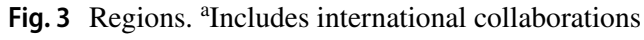

patients with untreated anaemia incurred $17 \%$ higher direct costs than patients with treated anaemia (Table 3, Fig. 4). Using a similar study design, Maddux et al. [43] concluded that ESA-untreated patients incurred 22.8\% higher direct costs than treated patients (Table 3, Fig. 4). In a longitudinal retrospective study, Papatheofanis et al. [42] reported healthcare cost savings of \$US4417 per patient per year after patients initiated ESA treatment (relative to baseline; Table 3).

Two studies with sample sizes ranging between 438 and 1432 compared the costs associated with aiming for higher and lower haemoglobin targets using ESAs [23, 39]. With respect to HRU, an RCT by Singh et al. [23] reported that the proportion of patients with hospitalization for a cardiovascular cause was $5 \%$ higher in patients randomized to achieve a higher haemoglobin target than in patients randomized to achieve a lower haemoglobin target (Table 3 ). In a costutility analysis, Clement et al. [39] reported that the costs of aiming for a haemoglobin target $>12 \mathrm{~g} / \mathrm{dL}$ were higher than those of aiming for a target of $9.0-10.9 \mathrm{~g} / \mathrm{dL}$ (Table 3).

\section{Discussion}

The clinical guidelines and treatment landscape for the management of anaemia of CKD have substantially evolved in the past decade. Furthermore, regional differences in the disease management of CKD-related anaemia make it difficult to compare studies and summarize existing evidence across regions. Thus, a global updated assessment of the cost and HRQoL burden of anaemia of CKD is much needed. This SLR qualitatively assessed the cost and HRQoL burden of anaemia of CKD in patients with NDD-CKD in a narrative synthesis of 16 studies. All eligible studies focused on ESAs, and some also reported on iron as a concomitant treatment. In general, HRQoL benefits associated with higher haemoglobin targets appeared modest and of uncertain clinical significance [16, 37-39, 44, 49]. However, improvements in the domain of 'vitality' were observed in two studies [37, 49]. Studies generally reported higher overall HRQoL in ESA-treated patients than in untreated patients [45-48], although one real-world study noted that ESA/iron treatment was associated with lower HRQoL [14]. In addition, studies showed that aiming for higher versus lower haemoglobin targets was associated with higher HRU and costs, and lower gains in QALY [23, 39]. However, despite the high acquisition costs of ESAs, leaving anaemia of CKD untreated resulted in higher costs and HRU [41-43, 46]; this finding highlights the importance of treating this condition from an economic standpoint. In summary, results from this narrative synthesis shed light on the unmet needs of patients with NDD-CKD and the substantial burden of current treatment.

\subsection{Impact of Higher Haemoglobin Targets on HRQoL}

Aiming for higher haemoglobin targets led to seemingly modest HRQoL benefits compared with aiming for lower targets. While there is a clear association between haemoglobin levels and HRQoL [16, 50-52], treating patients to currently unachievable high levels of haemoglobin (not allowed per guidelines, high cost or lack of response) seems to have mitigated effects on HRQoL. The impact on fatigue-related domains appeared more pronounced in two RCTs, as "vitality' was the only SF-36 domain with clinically and statistically meaningful improvements for patients randomized in higher haemoglobin target groups. The most significant HRQoL improvements ensuing from anaemia treatment are typically related to physical symptoms and fatigue, while other domains are more marginally improved [53].

A study by Clement et al. [39] reported on the impact of different haemoglobin targets on the QALYs and costs of patients with anaemia of CKD. With respect to QALYs, the authors found that the gains in QALY became more limited when aiming for haemoglobin targets above $12 \mathrm{~g} / \mathrm{dL}$. Similar results were obtained in a more recent cost-effectiveness analysis by Yarnoff et al. [54], which was not included in the present study since it did not focus on the impact of a particular treatment. Together, these findings may reflect the higher risks of MACE associated with ESAs and the high doses of ESAs required to achieve high haemoglobin levels.

Among the pivotal trials that included HRQoL assessments, the CHOIR trial found non-statistically significant improvements in HRQoL, whereas the CREATE trial reported HRQoL improvements across all SF-36 domains assessed [22, 23, 55]. Part of this discrepancy might be explained by the fact that the CHOIR trial, unlike the CREATE trial, censored patients at KRT initiation (i.e. some patients became DD during the course of the study period). This also explains the exclusion of CREATE in the current 
Table 2 Summary of findings: health-related quality of life

\begin{tabular}{|c|c|c|}
\hline Study & Treated versus untreated patients & High versus low $\mathrm{Hb}$ target or $\mathrm{Hb}$ levels \\
\hline Akizawa et al. [37] & - & $\begin{array}{l}\text { SF-36 } \\
\text { - Vitality: higher for } \mathrm{Hb}=11.0-13.0 \mathrm{~g} / \mathrm{dL} \text { (MCID } \\
\text { reached, } P<0.05 \text { ) }\end{array}$ \\
\hline Clement et al. [39] & - & $\begin{array}{l}\text { QALYs gained (relative to no ESA treatment) } \\
\bullet \mathrm{Hb}=9.0-10.9 \mathrm{~g} / \mathrm{dL}: 0.65 \\
\bullet \mathrm{Hb}=11.0-12.0 \mathrm{~g} / \mathrm{dL}: 0.51 \\
-\mathrm{Hb}>12.0 \mathrm{~g} / \mathrm{dL}: 0.30\end{array}$ \\
\hline De Goeij et al. [38] & - & $\begin{array}{l}\text { SF-36 } \\
\text { - Bodily pain, vitality, social functioning, mental sum- } \\
\text { mary: lower for } \mathrm{Hb}<11 \mathrm{~g} / \mathrm{dL} \text { vs. } \mathrm{Hb}=11.0-12.0 \mathrm{~g} / \mathrm{dL} \\
\text { (MCID reached; } P<0.05 \text { ) } \\
\text { - Physical functioning, physical summary: higher for } \\
\mathrm{Hb} \geq 13 \mathrm{~g} / \mathrm{dL} \text { than } \mathrm{Hb}=11.0-12.0 \mathrm{~g} / \mathrm{dL} \text { (MCID } \\
\text { reached; } P<0.05 \text { ) } \\
\text { - General health: higher for } \mathrm{Hb} \geq 13.0 \mathrm{~g} / \mathrm{dL} \text { than } \mathrm{Hb}= \\
11.0-12.0 \mathrm{~g} / \mathrm{dL} \text {, but not clinically meaningful }(\mathrm{MCID} \\
\text { not reached; } P<0.05 \text { ) }\end{array}$ \\
\hline Eriksson et al. [14] & $\begin{array}{l}\text { KDQoL-36 (ESA/iron-treated vs. non-ESA/iron-treated } \\
\text { patients) } \\
\text { - Physical composite summary (stage } 3 \& 4 \text { ), mental com- } \\
\text { posite summary (stage } 3 \& 4 \text { ): higher in non-ESA/iron- } \\
\text { treated patients, but not clinically meaningful (MCIDs } \\
\text { not reached; } P<0.05 \text { ) }\end{array}$ & - \\
\hline Finkelstein et al. [16] & - & $\begin{array}{l}\text { KDQoL-36 } \\
\text { - EQ-5D index (stage } 3 \text { and 4), symptom problem, effects } \\
\text { kidney disease, burden of kidney disease, work status, } \\
\text { sleep, symptom problem, effects kidney disease, burden } \\
\text { kidney disease, work status, role-emotional, social } \\
\text { function, energy/fatigue: increased with higher Hb } \\
\text { levels (MCID reached; } P<0.05 \text { ) } \\
\text { - Cognitive function: higher with high Hb levels, but not } \\
\text { clinically meaningful (MCID not reached; } P<0.05 \text { ) }\end{array}$ \\
\hline Hirakata et al. [40] & $\begin{array}{l}\text { SF-36 } \\
\text { - Role-physical, general health, vitality: improved (MCID } \\
\text { reached; } P<0.05 \text { ) } \\
\text { FACIT-Fatigue } \\
\text { - FACIT-Fatigue: improved (MCID reached; } P<0.05 \text { ) }\end{array}$ & \\
\hline Islam et al. [45] & $\begin{array}{l}\text { Customized approach } \\
\text { - Normal sense of wellbeing, good appetite, normal physi- } \\
\text { cal activity: improved (MCID does not apply; } P<0.05 \text { ) }\end{array}$ & - \\
\hline Kawaguchi et al. [44] & - & $\begin{array}{l}\text { SF-36 } \\
\bullet \text { No domains improved (MCID not reached; } P>0.05 \text { ) }\end{array}$ \\
\hline Lewis et al. [47] & $\begin{array}{l}\text { SF-36 } \\
\text { - Energy, physical function, role physical: higher in } \\
\text { treatment arm, but not clinically meaningful (MCID not } \\
\text { reached; } P<0.05 \text { ) } \\
\text { FACT-Fatigue } \\
\text { - FACT-Fatigue: higher in treatment arm, but not clini- } \\
\text { cally meaningful (MCID not reached; } P<0.05 \text { ) } \\
\text { EQ-5D } \\
\text { - EQ-5D index: higher in treatment arm (MCID reached; } \\
P<0.05 \text { ) }\end{array}$ & - \\
\hline Provenzano et al. [46] & $\begin{array}{l}\text { KDQ } \\
\text { - Physical symptoms, fatigue, depression, relationship } \\
\text { with others, frustration: improved (MCID reached, } \\
P<0.05 \text { ) } \\
\text { LASA } \\
\text { - Energy, activity, overall QoL: improved (MCID reached; } \\
P<0.05 \text { ) }\end{array}$ & - \\
\hline
\end{tabular}


Table 2 (continued)

\begin{tabular}{|c|c|c|}
\hline Study & Treated versus untreated patients & High versus low $\mathrm{Hb}$ target or $\mathrm{Hb}$ levels \\
\hline Roger et al. [48] & $\begin{array}{l}\text { SF-36 } \\
\text { - Physical function, role-physical, bodily pain, physical } \\
\text { component: higher in treatment arm (MCID reached; } \\
P \text { s }<0.05 \text { ) } \\
\text { - Vitality, social functioning, mental health: similar } \\
\text { (MCID reached; } P>0.05 \text { ) } \\
\text { FACT-Fatigue } \\
\text { - Anaemia, and total score: higher in treatment arm } \\
\text { (MCID reached; } P<0.05 \text { ) } \\
\text { - Function: higher in treatment arm, but not clinically } \\
\text { meaningful (MCID not reached, } P<0.05 \text { ) }\end{array}$ & - \\
\hline Rossert et al. [49] & - & $\begin{array}{l}\text { SF-36 } \\
\text { - Vitality: higher for } \mathrm{Hb}=13.0-15.0 \mathrm{~g} / \mathrm{dL} \text { (MCID } \\
\text { reached, } P<0.05 \text { ) } \\
\text { - Physical function, physical role, emotional role: similar } \\
\text { (MCID reached; } P>0.05 \text { ) }\end{array}$ \\
\hline Singh et al. [23] & & $\begin{array}{l}\text { SF-36 } \\
\text { - Emotional role: higher for } \mathrm{Hb} \text { target }=13.5 \mathrm{~g} / \mathrm{dL} \text { (MCID } \\
\text { reached; } P<0.05 \text { ) } \\
\text { LASA } \\
\text { - No domains improved (MCIDs not reached; Ps }<0.05 \text { ) } \\
\text { KDQ } \\
\text { - Total score: similar (MCID reached; } P>0.05 \text { ) }\end{array}$ \\
\hline
\end{tabular}

EQ-5D EuroQol-5 Dimensions, ESA erythropoiesis-stimulating agent, FACIT Fatigue Functional Assessment of Chronic Illness Therapy Fatigue, FACT Fatigue Functional Assessment of Cancer Therapy - Fatigue, $H b$ haemoglobin, $K D Q$ Kidney Disease Questionnaire, KDQoL Kidney Disease Quality of Life, $L A S A$ linear analogue self-assessment, $M C I D$ minimal clinically important difference, $Q A L Y$ quality-adjusted life-year, $Q o L$ quality of life, $S F$-36 36-item Short Form Health Survey

SLR, as patients were not NDD throughout the complete duration of follow-up. Another difference that may contribute to this discrepancy is that patients included in the CHOIR trial had lower baseline haemoglobin levels and required ESA doses twice as high as those used in the CREATE trial to achieve similar haemoglobin levels.

\subsection{Impact of Treatment of Anaemia on HRQoL}

Two RCTs and two single-arm trials assessed the HRQoL impact of treating anaemia of CKD compared with nontreatment. In general, clinically meaningful improvements in HRQoL were achieved following treatment of anaemia of CKD with ESAs. A noteworthy exception is the cross-sectional study conducted by Eriksson et al. [14], who reported better HRQoL among ESA-untreated/iron-untreated than ESA and/or iron-treated patients. Furthermore, there may be differences between the recommended management of anaemia of CKD practiced during an RCT and that observed in clinical practice as reported in the cross-sectional study. Due to the limited number of eligible real-world studies (only three) that investigated HRQoL, it is challenging to confirm this hypothesis. Further research is warranted to address the paucity of real-world data on the HRQoL of patients with NDD-CKD.
Collister et al. [34] recently published a meta-analysis reviewing the impact of ESAs on the HRQoL of patients with anaemia of CKD. The authors did not find clinically or statistically significant differences in HRQoL associated with higher haemoglobin targets, which has been interpreted as an absence of meaningful positive impact of ESAs on HRQoL. The results from the present SLR suggest a more cautious conclusion should be drawn: ESAs do have an impact on HRQoL when ESA-treated patients are compared with their untreated counterparts. However, relative to aiming for lower haemoglobin targets, ESA treatment with high haemoglobin targets provides, at best, modest HRQoL benefits. This may be partially explained by the inclusion of study designs other than RCTs in the current SLR, such as prospective observational studies, prospective single-arm trials, and retrospective studies.

With respect to the impact of iron treatment on HRQoL, only one study matching our search criteria investigated this question, and it focused on the effects of oral versus intravenous iron treatment. The authors found higher improvements in KDQ scores for patients treated with intravenous iron. Both routes of administration led to improvements in haemoglobin levels that appeared much smaller than those commonly observed with ESAs (i.e. oral: $+0.2 \mathrm{~g} / \mathrm{dL}$, intravenous: $+0.4 \mathrm{~g} / \mathrm{dL}$ ) [56]. 
Table 3 Summary of findings: Costs ${ }^{\mathrm{a}}$

\begin{tabular}{|c|c|c|}
\hline Study & Treated versus untreated patients & High versus low $\mathrm{Hb}$ target or $\mathrm{Hb}$ levels \\
\hline Clement et al. [39] & - & $\begin{array}{l}\text { Direct costs } \\
\text { - Higher costs when aiming for an } \mathrm{Hb} \text { target }>12 \mathrm{~g} / \mathrm{dL} \text { relative } \\
\text { to aiming for an } \mathrm{Hb} \text { target }=9.0-10.9 \mathrm{~g} / \mathrm{dL}\end{array}$ \\
\hline Maddux et al. [43] & $\begin{array}{l}\text { Direct costs } \\
\text { - ESA-treated patients had lower total healthcare costs than ESA- } \\
\text { untreated patients (\$US3876 vs. } 4758 \text { PPPM, } P<0.05 \text { ) }\end{array}$ & - \\
\hline Papatheofanis et al. [42] & $\begin{array}{l}\text { Direct costs } \\
\text { - Total monthly employer costs (medical and pharmacy costs) fell } \\
\text { from \$US1710.90 PPPM to \$US1342.79 after initiating EPO, } \\
\text { yielding a \$US4417 PPPY decrease in costs } \\
\text { Indirect costs } \\
\text { - } 91.5 \% \text { increase in productivity (from } 217 \text { SKU/week } \\
\text { [1-3 months pre-EPO] to } 416 \text { SKU/week [4-6 months post- } \\
\text { EPO]) and } 52.3 \text { days PPPY decrease in absenteeism (from } \\
2.82 \text { days per week [1-3 months pre-EPO] to } 3.91 \text { days per } \\
\text { week [4-6 months post-EPO]) after epoetin initiation relative } \\
\text { to the pre-EPO period }\end{array}$ & - \\
\hline Provenzano et al. [46] & $\begin{array}{l}\text { HRU } \\
\text { - The proportion of patients that required RBCT after initiating } \\
\text { ESA treatment decreased from } 11.1 \text { to } 3.7 \%(P<0.05)\end{array}$ & \\
\hline Singh et al. [23] & - & $\begin{array}{l}\text { HRU } \\
\text { - } 5.1 \% \text { higher risk ( } 32.6 \text { vs. } 27.5 \%) \text { of having a hospitalization } \\
\text { with a cardiovascular cause for patients randomized in the } \\
\text { high Hb target group }(P<0.05) \\
\text { - } 5.0 \% \text { higher risk }(51.6 \text { vs. } 46.6 \%) \text { of having a hospitalization } \\
\text { for any cause for patients randomized in the high Hb target } \\
\text { group }(P<0.05)\end{array}$ \\
\hline Wish et al. [41] & $\begin{array}{l}\text { Direct costs } \\
\text { - 17\% higher overall costs for untreated patients (\$US4470 } \\
\text { PPPM) than treated patients (\$US3806 PPPM) }\end{array}$ & - \\
\hline
\end{tabular}

$E P O$ erythropoietin, $E S A$ erythropoiesis-stimulating agent, $H b$ haemoglobin, $H R U$ healthcare resource utilization, $P P P M$ per patient per month, $P P P Y$ per patient per year, $R B C T$ red blood cell transfusion, $S K U$ Stock keeping units

${ }^{\mathrm{a}}$ Costs and cost differences presented in this table are presented as reported in the original publication

Fig. 4 Cost outcomes among studies that compared treated vs. untreated patients. ESA erythropoiesis-stimulating agent, $P P P M$ per patient per month, $R B C T$ red blood cell transfusion

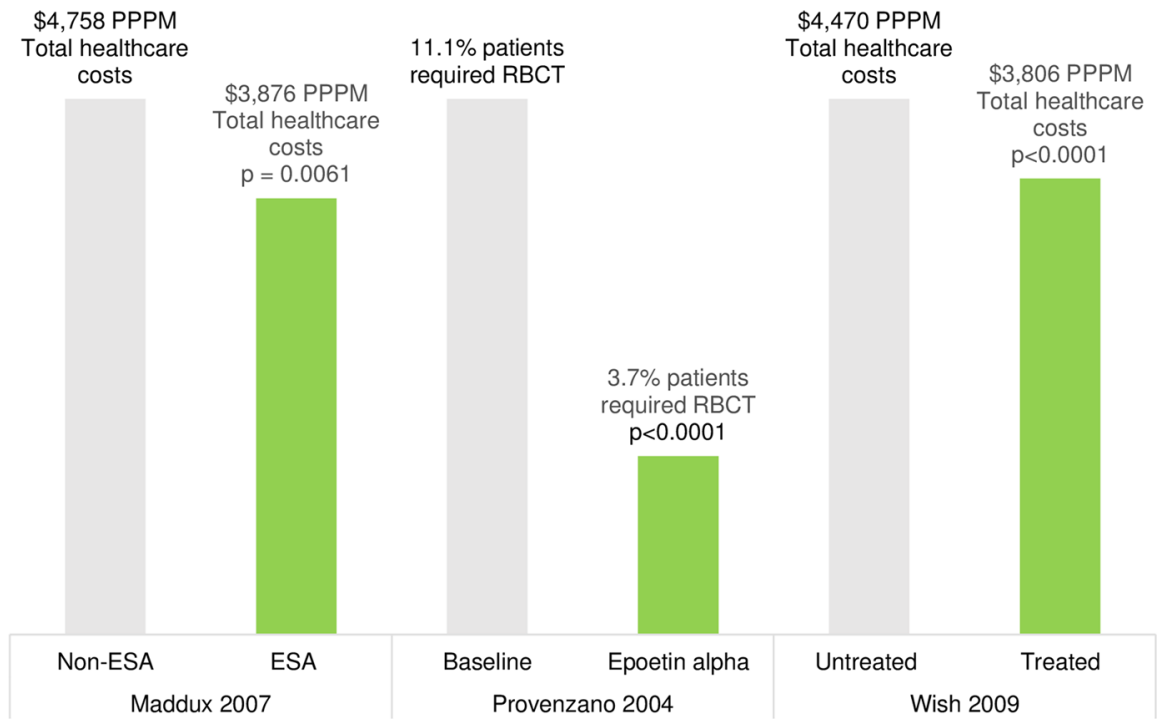




\subsection{Impact of Higher Haemoglobin Targets on Costs}

With respect to costs, the cost-utility analysis conducted by Clement et al. [39] found that gains in QALYs associated with haemoglobin targets above $12 \mathrm{~g} / \mathrm{dL}$ required much higher costs, a conclusion also drawn by Yarnoff et al. [54]. This may be explained by a higher incidence of MACE when aiming for such targets. In support of this hypothesis, one RCT included in the present review found that patients randomized to achieve a higher haemoglobin target with ESAs had higher HRU [23].

\subsection{Impact of Treatment of Anaemia on Costs}

Four included studies consistently showed that the nontreatment of anaemia of CKD is associated with higher HRU and costs. One study by Provenzano et al. [46] showed that untreated patients had higher HRU than ESA-treated patients, and three studies showed that non-treatment was associated with significantly higher costs than was treatment [41-43]. Notably, the study by Provenzano et al. [46] was prospective, whereas the three other studies that reported on costs had a retrospective design, which further highlights the robustness of these conclusions with regards to study designs. Collectively, this suggests that, within the current standard of care framework, the higher acquisition costs of ESAs are offset by lower medical costs [41, 43].

As a cost-lowering alternative, epoetin biosimilars have been available in Europe since 2007 [57], and RETACRIT ${ }^{\circledR}$ became the first approved epoetin biosimilar in the USA in mid-2018. Biosimilars were estimated to have led to savings representing $15-30 \%$ of the price of the reference agent [58], suggesting savings of similar magnitude can be anticipated with biosimilar ESAs. Presumably due to initial safety, efficacy, and manufacturing concerns experienced in poorly regulated countries, biosimilars do not have a good reputation among certain providers and regulators. This likely accounts for the apparent underuse of biosimilar epoetin in some European countries [59, 60], which limits our understanding of how this may affect healthcare costs for anaemia of CKD.

\subsection{Limitations}

Findings of this literature summary review should be considered in light of several limitations. First, some studies may have been missed despite the scope of the rigorous search strategy used in the current SLR. For instance, studies that focused on 'treatments' as a whole, and did not specify the names of specific treatments, may not have been identified by the electronic search strategy. Second, because studies were heterogeneous in terms of study designs and choices of outcomes (e.g. choice of HRQoL measurements, HRQoL domains reported, HRU vs. costs reported, etc.), this review could not quantitatively summarize study conclusions using a meta-analysis. Third, while a rigid cut-off derived from the literature was applied to HRQoL findings, an MCID should ideally be determined using study-specific elements. For instance, studies that included patients with better baseline performance status are less likely to report higher improvements due to a ceiling effect, which shows the importance of adapting the MCID to each study [61]. Finally, the risk of bias and quality of reporting were not assessed because of the high heterogeneity in study designs.

\section{Conclusion}

In this literature review, non-treatment of patients with anaemia of CKD who were not on dialysis resulted in higher costs and was associated with poorer HRQoL, which emphasizes the need for treatment. However, aiming for haemoglobin targets higher than $12 \mathrm{~g} / \mathrm{dL}$ led to seemingly modest HRQoL improvements of uncertain clinical significance, although improvements in the vitality domain appeared more robust than those in other domains. Effective treatment options with improved safety profiles are needed to improve the HRQoL of these patients with anaemia of CKD.

Acknowledgements The study was funded by Akebia Therapeutics, Inc. Editorial assistance was provided by Analysis Group, Inc. The authors thank Bostjan Ceh, Sunil Navani, Zalmai Hakimi, Jing WangSilvanto (of Otsuka Pharmaceutical Europe Ltd) and Andrew Garnham (of Clear Health Economics, London) for editorial comments and Marie-Hélène Lafeuille, Farzin Khosrow-Khavar, and Laure-Anne Damasse (of Analysis Group, Inc.) for help with the initial search strategy design and execution. This study was funded by Akebia Therapeutics, Inc (Akebia).

Author Contributions All authors participated in the study design and interpretation of the data. Data analysis and original drafting of this manuscript were performed by SR and PT-L. All authors have provided critical feedback on the manuscript and approved the final version.

\section{Compliance with Ethical Standards}

Conflicts of interest PP received consulting fees from Akebia for work not related to this manuscript. RP-F participated in advisory boards 
from Akebia and Astra Zeneca and received honoraria from Akebia and AstraZeneca. WCW has received honoraria for unrelated work from Akebia, AMAG Pharma, Amgen, AstraZeneca, Bayer, DaichiiSankyo, Duke Clinical Research Institute, Fibrogen, Relypsa, Vifor Fresenius Medical Care Renal Pharma, and ZS Pharma. BS has participated in clinical trials for the treatment of anaemia on behalf of Akebia. SR, PT-L, and PL are employees of Analysis Group, Inc., a consulting company that received funding from Akebia Therapeutics Inc. to conduct this study. GS is an employee and stockholder of Akebia Therapeutics. AB is a former employee of Akebia and owns Akebia stock and stock options. MS and HBK are employees of Otsuka Pharmaceutical Development \& Commercialization, Inc., a collaboration partner of Akebia in the development of vadadustat for the treatment of anaemia secondary to CKD.
Statement of human rights This article does not contain any studies with human participants performed by any of the authors.

Data availability Data sharing is not applicable to this article as no datasets were generated or analysed during the current study.

Open Access This article is distributed under the terms of the Creative Commons Attribution-NonCommercial 4.0 International License (http://creativecommons.org/licenses/by-nc/4.0/), which permits any noncommercial use, distribution, and reproduction in any medium, provided you give appropriate credit to the original author(s) and the source, provide a link to the Creative Commons license, and indicate if changes were made.

\section{Appendix 1: Search Strategy}

\section{1}

Dialysis or h?emodialysis or h?emofiltration or h?emodiafiltration or endstage renal or endstage kidney or endstage renal or end-stage kidney or ESRF or ESKF or ESRD or ESKD or chronic kidney or chronic renal or $\mathrm{CKF}$ or CKD or CRF or CRD or CAPD or CCPD or APD or predialysis or pre-dialysis or ur?emi\$

((Kidney or renal) and disease) or ((Kidney or renal) and insufficiency) or ((Kidney or renal) and dysfunction) or ((Kidney or renal) and failure) or (Exp kidney disease/) or (Exp renal disease/) or (Exp kidney insufficiency/) or (Exp kidney dysfunction/) or (Exp kidney failure/)

economic OR cost OR burden OR landscape OR caregiver OR indirect OR "quality of life" or "qol" or "HRQOL" or "patient-reported outcome" erythropoiesis-stimulating agent\$ or erythropoiesis stimulating agent\$ or "ESA" or epoetin or epoetin alfa or Epogen or Procrit or darbepoetin or darbepoetin alfa or Aranesp$$
\text { Iron or ferrous or ferric or (Exp iron/) }
$$$$
\text { (1 or } 2)
$$$$
\text { (1 or } 2 \text { ) filter humans }
$$$$
\text { (1 or 2) filter humans and } 3
$$$$
\text { (1 or 2) filter humans and } 3 \text { and } 4
$$$$
\text { (1 or 2) filter humans and } 3 \text { and } 4 \text { and (5) }
$$$$
12 \text { de-duplicated, in English, from } 2000 \text { onwards }
$$$$
13 \text { excluding letters, interviews, editorials, comments, biographies, and addresses }
$$$$
14 \text { restricted to adult populations }
$$$$
\text { ( } 1 \text { or } 2 \text { ) filter humans and } 3 \text { and } 4 \text { and (5 or } 6 \text { ) }
$$$$
16 \text { de-duplicated, in English, from } 2000 \text { onwards }
$$$$
17 \text { excluding letters, interviews, editorials, comments, biographies, and addresses }
$$$$
18 \text { restricted to adult populations }
$$$$
\text { ( } 1 \text { or } 2 \text { ) filter humans and } 3 \text { and } 4 \text { and (5 or } 6 \text { or } 7 \text { ) }
$$$$
20 \text { de-duplicated, in English, from } 2000 \text { onwards }
$$$$
21 \text { excluding letters, interviews, editorials, comments, biographies, and addresses }
$$

674,463

$1,637,730$

(1) Search conducted on 17 March 2017

(2) Search conducted in MEDLINE, MEDLINE In-Process, Embase, CENTRAL, CDSR, NHS EED and NHS HTA using OvidSP

(3) Search conducted using “.MP” field in OvidSP, which searches title, original title, abstract, subject heading, name of substance, and registry word fields 


\section{Appendix 2: List of extracted variables}

- Author(s)

- Year of publication

- Title

- Intervention(s) (i.e. ESAs, and/or RBCT and/or iron/ferric supplementation)

- Country(ies) in which the study was conducted

- Study design

- Time period of data collection analysis

- Hb target/guideline(s) followed

- Dates of data collection

- Dose/dosing schedule
- Treatment duration

- Eligibility criteria (i.e. inclusion and exclusion criteria)

- Number of patients included in the analysis

- Patient characteristics at study initiation (i.e. mean age, sex, CKD stage, type of dialysis and months on dialysis, comorbidities, and laboratory measurements)

- HRQoL outcomes (measured with KDQoL-36 and KDQoL-12, SF-36 and SF-12, QALYs, fatigue score, 6-minute walking test, physical activity, KDQ-13, KDQ26, other measurements)

- Cost outcomes (HRU, cost per QALY, treatment-related costs, other direct costs, and indirect costs)

\section{Appendix 3: Minimal clinically important difference thresholds used to determine the clinical significance of $\mathrm{HRQ} \mathrm{OL}$ changes in the narrative synthesis}

\begin{tabular}{|c|c|c|c|c|c|}
\hline Questionnaire & $\begin{array}{l}\text { Disease-specific } \\
\text { (yes/no, disease and } \\
\text { population name) }\end{array}$ & $\begin{array}{l}\text { Populations where } \\
\text { validated (DD/ } \\
\text { NDD) }\end{array}$ & $\begin{array}{l}\text { Typical range of } \\
\text { MCID }\end{array}$ & $\begin{array}{l}\text { MCID value used } \\
\text { as threshold }\end{array}$ & References \\
\hline SF-12/36 & No & DD & $3-5$ & 4 & $\begin{array}{l}\text { Leaf } 2009 \text { Kidney Int 75: 15-24 } \\
\text { Eriksson } 2017 \text { Nephrol Dial } \\
\text { Transpl 32(12):2106-11 }\end{array}$ \\
\hline KDQoL-12/36 & Yes, CKD & DD & $3-5$ & 4 & $\begin{array}{l}\text { Leaf } 2009 \text { Kidney Int 75: 15-24 } \\
\text { Eriksson } 2017 \text { Nephrol Dial } \\
\text { Transpl 32(12):2106-11 }\end{array}$ \\
\hline KDQ & Yes, CKD & DD & 0.5 & 0.5 & Leaf 2009 Kidney Int 75: 15-24 \\
\hline EQ-5D & No & - & $0.06-0.08$ & 0.07 & Leaf 2009 Kidney Int $75: 15-24$ \\
\hline LASA & No & - & $10-20$ & 15 & $\begin{array}{l}\text { Cella } 2002 \text { J Pain Symp Man 24: } \\
\text { 547-561 }\end{array}$ \\
\hline FACIT-Fatigue scale & $\begin{array}{l}\text { Hybrid (targeted } \\
\text { and specific) }\end{array}$ & $\begin{array}{l}\text { Iron-deficiency ane- } \\
\text { mia (in general) }\end{array}$ & 3.0 & 3.0 & $\begin{array}{l}\text { Bohannon } 2016 \text { J Eval Clin Pract } \\
\text { 23(2):377-381 }\end{array}$ \\
\hline FACT-Fatigue scale & Yes, cancer & - & 3.0 & 3.0 & $\begin{array}{l}\text { Leaf } 2009 \text { Kidney Int 75: 15-24 } \\
\text { Eriksson } 2017 \text { Nephrol Dial } \\
\text { Transpl 32(12):2106-11 }\end{array}$ \\
\hline
\end{tabular}

$C K D$ chronic kidney disease, $D D$ dialysis dependent, $E Q-5 D$ EuroQol-5 Dimensions, FACIT Fatigue Functional Assessment of Chronic Illness Therapy-Fatigue, KDQoL Kidney Disease Quality of Life, LASA linear analogue self-assessment, MCID minimal clinically important difference, $N D D$ non-dialysis-dependent, $S F-12 / 36$ 12- or 36-item Short Form Health Survey 


\section{References}

1. Kidney Disease: Improving Global Outcomes (KDIGO) CKD Work Group. KDIGO 2012 clinical practice guideline for the evaluation and management of chronic kidney disease. Kidney Inter Suppl. 2012;2013(3):1-150.

2. Glassock RJ, Warnock DG, Delanaye P. The global burden of chronic kidney disease: estimates, variability and pitfalls. Nat Rev Nephrol. 2017;13(2):104-14.

3. National Kidney Foundation. KDOQI clinical practice guideline for diabetes and CKD: 2012 update. Am J Kidney Dis. 2012;60(5):850-86.

4. Thomas MC, Brownlee M, Susztak K, Sharma K, Jandeleit-Dahm KA, Zoungas S, et al. Diabetic kidney disease. Nat Rev Dis Primers. 2015;1:15018.

5. United States Renal Data System. Chapter 5: Mortality 2017. https://www.usrds.org/2017/download/v2_c05_Mortality_17. pdf. Accessed 23 Aug 2018.

6. United States Renal Data System. 2017 USRDS Annual Data Report: Executive Summary 2017 https://www.usrds.org/2017/ download/v1_00_ExecSummary_17.pdf. Accessed 29 May 2018.

7. Braun L, Sood V, Hogue S, Lieberman B, Copley-Merriman C. High burden and unmet patient needs in chronic kidney disease. Int J Nephrol Renovasc Dis. 2012;5:151-63.

8. Wang V, Vilme H, Maciejewski ML, Boulware LE. The economic burden of chronic kidney disease and end-stage renal disease. Semin Nephrol. 2016;36(4):319-30.

9. Pugh-Clarke K, Read SC, Sim J. Symptom experience in nondialysis-dependent chronic kidney disease: a qualitative descriptive study. J Ren Care. 2017;43(4):197-208.

10. Golestaneh L, Alvarez PJ, Reaven NL, Funk SE, McGaughey $\mathrm{KJ}$, Romero A, et al. All-cause costs increase exponentially with increased chronic kidney disease stage. Am J Manag Care. 2017;23(10 Suppl):S163-72.

11. Ryan TP, Sloand JA, Winters PC, Corsetti JP, Fisher SG. Chronic kidney disease prevalence and rate of diagnosis. Am J Med. 2007;120(11):981-6.

12. United States Renal Data System. Chapter 6: Medicare Expenditures for CKD [Available from: https://www.usrds.org/2014/view/ v1_06.aspx. Accessed 8 Nov 2018.

13. Edey MM. Male sexual dysfunction and chronic kidney disease. Front Med (Lausanne). 2017;4:32.

14. Eriksson D, Goldsmith D, Teitsson S, Jackson J, van Nooten F. Cross-sectional survey in CKD patients across Europe describing the association between quality of life and anaemia. BMC Nephrol. 2016;17(1):97.

15. Farag YM, Keithi-Reddy SR, Mittal BV, Surana SP, Addabbo F, Goligorsky MS, et al. Anemia, inflammation and health-related quality of life in chronic kidney disease patients. Clin Nephrol. 2011;75(6):524-33.

16. Finkelstein FO, Story K, Firanek C, Mendelssohn D, Barre P, Takano T, et al. Health-related quality of life and hemoglobin levels in chronic kidney disease patients. Clin J Am Soc Nephrol. 2009;4(1):33-8.

17. Lefebvre P, Vekeman F, Sarokhan B, Enny C, Provenzano R, Cremieux PY. Relationship between hemoglobin level and quality of life in anemic patients with chronic kidney disease receiving epoetin alfa. Curr Med Res Opin. 2006;22(10):1929-37.

18. Pai MF, Hsu SP, Yang SY, Ho TI, Lai CF, Peng YS. Sleep disturbance in chronic hemodialysis patients: the impact of depression and anemia. Ren Fail. 2007;29(6):673-7.

19. Stauffer ME, Fan T. Prevalence of anemia in chronic kidney disease in the United States. PLoS One. 2014;9(1):e84943.
20. Kidney Disease: Improving Global Outcomes (KDIGO) Anemia Work Group. KDIGO clinical practice guideline for anemia in chronic kidney disease. Kidney Inter Suppl. 2012;2:279-335.

21. Pfeffer MA, Burdmann EA, Chen CY, Cooper ME, de Zeeuw D, Eckardt KU, et al. A trial of darbepoetin alfa in type 2 diabetes and chronic kidney disease. N Engl J Med. 2009;361(21):2019-32.

22. Drueke TB, Locatelli F, Clyne N, Eckardt KU, Macdougall IC, Tsakiris D, et al. Normalization of hemoglobin level in patients with chronic kidney disease and anemia. N Engl J Med. 2006;355(20):2071-84.

23. Singh AK, Szczech L, Tang KL, Barnhart H, Sapp S, Wolfson $\mathrm{M}$, et al. Correction of anemia with epoetin alfa in chronic kidney disease. N Engl J Med. 2006;355(20):2085-98.

24. United States Renal Data System. 2017 USRDS annual data report. 2017.

25. US Food and Drug Administration. FDA Drug Safety Communication: Modified dosing recommendations to improve the safe use of Erythropoiesis-Stimulating Agents (ESAs) in chronic kidney disease 2011. https://www.fda.gov/Drugs/DrugSafety/ucm25 9639.htm. Accessed 7 Feb 2018.

26. European Medicines Agency. NeoRecormon-epoetin beta. http://www.ema.europa.eu/docs/en_GB/document_library/ EPAR_-_Product_Information/human/000116/WC50002497 9.pdf. Accessed 14 Feb 2018.

27. European Medicines Agency. Aranesp - darbepoetin alfa. http:// www.ema.europa.eu/docs/en_GB/document_library/EPAR_Product_Information/human/000332/WC500026149.pdf. Accessed 14 Feb 2018.

28. Japanese Society of Nephrology. Evidence-based clinical practice guideline for CKD 2013. Clin Exp Nephrol. 2014;18(3):346-423.

29. Evans M, Suttorp MM, Bellocco R, Hoekstra T, Qureshi AR, Dekker FW, et al. Trends in haemoglobin, erythropoietinstimulating agents and iron use in Swedish chronic kidney disease patients between 2008 and 2013. Nephrol Dial Transpl. 2016;31(4):628-35.

30. St. Peter WL, Guo H, Kabadi S, Zhao S, Gilbertson DT, Sargent Heuer LJ, et al. FR-PO767: Anemia treatment pattern changes in non-dialysis-dependent chronic kidney disease patients before and after revised food and drug administration label and new anemia guidelines for erythropoiesis-stimulating agents. J Am Soc Nephrol. 2016;27:542A.

31. Wong MMY, Tu C, Zepel L, Combe C, Lopes AA, Pecoits-Filho $\mathrm{R}$, et al. SO037: anemia prevalence and treatment among patients with chronic kidney disease stage 3-5: data from the chronic kidney disease outcomes and practice patterns study (CKDOPPS). Nephrol Dial Transpl. 2016;31(Supplement 1):i15-7.

32. Akizawa T, Okumura H, Alexandre AF, Fukushima A, Kiyabu G, Dorey J. PUK26 - burden of illness associated with anaemia in chronic kidney disease in Japan: a literature review. Value in Health. 2017;20(9):A492.

33. van Nooten FE, Green J, Brown R, Finkelstein FO, Wish J. Burden of illness for patients with non-dialysis chronic kidney disease and anemia in the United States: review of the literature. J Med Econ. 2010;13(2):241-56.

34. Collister D, Komenda P, Hiebert B, Gunasekara R, Xu Y, Eng $\mathrm{F}$, et al. The effect of erythropoietin-stimulating agents on health-related quality of life in anemia of chronic kidney disease: a systematic review and meta-analysis. Ann Intern Med. 2016;164(7):472-8.

35. Travers K, Martin A, Khankhel Z, Boye KS, Lee LJ. Burden and management of chronic kidney disease in Japan: systematic review of the literature. Int J Nephrol Renovasc Dis. 2013;6:1-13.

36. Remak E, Hutton J, Jones M, Zagari M. Changes in cost-effectiveness over time. The case of Epoetin Alfa for renal replacement therapy patients in the UK. Eur J Health Econ. 2003;4(2):115-21. 
37. Akizawa T, Gejyo F, Nishi S, Iino Y, Watanabe Y, Suzuki M, et al. Positive outcomes of high hemoglobin target in patients with chronic kidney disease not on dialysis: a randomized controlled study. Ther Apher Dial. 2011;15(5):431-40.

38. de Goeij MC, Meuleman Y, van Dijk S, Grootendorst DC, Dekker FW, Halbesma N, et al. Haemoglobin levels and health-related quality of life in young and elderly patients on specialized predialysis care. Nephrol Dial Transplant. 2014;29(7):1391-8.

39. Clement FM, Klarenbach S, Tonelli M, Wiebe N, Hemmelgarn B, Manns BJ. An economic evaluation of erythropoiesis-stimulating agents in CKD. Am J Kidney Dis. 2010;56(6):1050-61.

40. Hirakata H, Tsubakihara Y, Gejyo F, Nishi S, Iino Y, Watanabe $\mathrm{Y}$, et al. Maintaining high hemoglobin levels improved the left ventricular mass index and quality of life scores in pre-dialysis Japanese chronic kidney disease patients. Clin Exp Nephrol. 2010;14(1):28-35.

41. Wish J, Schulman K, Law A, Nassar G. Healthcare expenditure and resource utilization in patients with anaemia and chronic kidney disease: a retrospective claims database analysis. Kidney Blood Press Res. 2009;32(2):110-8.

42. Papatheofanis F, Bookhart BK, Muser E, Piech CT. An examination of productivity and resource utilization associated with epoetin alfa treatment in employees with predialysis chronic kidney disease. J Occup Environ Med. 2008;50(5):584-9.

43. Maddux FW, Shetty S, del Aguila MA, Nelson MA, Murray BM. Effect of erythropoiesis-stimulating agents on healthcare utilization, costs, and outcomes in chronic kidney disease. Ann Pharmacother. 2007;41(11):1761-9.

44. Kawaguchi T, Moriyama T, Suzuki K, Hatori M, Tanaka T, Takahara S, et al. Pilot study of the optimum hematocrit for patients in the predialysis stage after renal transplantation. Transpl Proc. 2004;36(5):1293-6.

45. Islam $\mathrm{S}$, Rahman $\mathrm{H}$, Rashid HU. Effect rHuEpo on predialysis CRF patients: study of 45 cases. Bangladesh Med Res Counc Bull. 2005;31(2):83-7.

46. Provenzano R, Garcia-Mayol L, Suchinda P, Von Hartitzsch B, Woollen SB, Zabaneh R, et al. Once-weekly epoetin alfa for treating the anemia of chronic kidney disease. Clin Nephrol. 2004;61(6):392-405.

47. Lewis EF, Pfeffer MA, Feng A, Uno H, McMurray JJ, Toto R, et al. Darbepoetin alfa impact on health status in diabetes patients with kidney disease: a randomized trial. Clin J Am Soc Nephrol. 2011;6(4):845-55.

48. Roger SD, Jassal SV, Woodward MC, Soroka S, McMahon LP. A randomised single-blind study to improve health-related quality of life by treating anaemia of chronic kidney disease with
$\operatorname{Aranesp}(\mathrm{R})$ (darbepoetin alfa) in older people: STIMULATE. Int Urol Nephrol. 2014;46(2):469-75.

49. Rossert J, Levin A, Roger SD, Horl WH, Fouqueray B, GassmannMayer C, et al. Effect of early correction of anemia on the progression of CKD. Am J Kidney Dis. 2006;47(5):738-50.

50. Lucca U, Tettamanti M, Mosconi P, Apolone G, Gandini F, Nobili A, et al. Association of mild anemia with cognitive, functional, mood and quality of life outcomes in the elderly: the "Health and Anemia" study. PLoS One. 2008;3(4):e1920.

51. Thein M, Ershler WB, Artz AS, Tecson J, Robinson BE, Rothstein $\mathrm{G}$, et al. Diminished quality of life and physical function in community-dwelling elderly with anemia. Medicine (Baltimore). 2009;88(2):107-14.

52. Rizzo M, Iheanacho I, van Nooten FE, Goldsmith D, editors. Poster MP198: A systematic literature review of the humanistic burden of anaemia associated with chronic kidney disease. ERAERDTA; 2014; Amsterdam.

53. Leaf DE, Goldfarb DS. Interpretation and review of health-related quality of life data in CKD patients receiving treatment for anemia. Kidney Int. 2009;75(1):15-24.

54. Yarnoff BO, Hoerger TJ, Simpson SA, Pavkov ME, Burrows NR, Shrestha SS, et al. The cost-effectiveness of anemia treatment for persons with chronic kidney disease. PLoS One. 2016;11(7): 0157323 .

55. Manns BJ, Tonelli M. The new FDA labeling for ESA-implications for patients and providers. Clin J Am Soc Nephrol. 2012;7(2):348-53.

56. Agarwal R, Rizkala AR, Bastani B, Kaskas MO, Leehey DJ, Besarab A. A randomized controlled trial of oral versus intravenous iron in chronic kidney disease. Am J Nephrol. 2006;26(5):445-54.

57. Horbrand F, Rottenkolber D, Fischaleck J, Hasford J. Erythropoietin-induced treatment costs in patients suffering from renal anemia-a comparison between biosimilar and originator drugs. Gesundheitswesen. 2014;76(11):e79-84.

58. Wish JB. The approval process for biosimilar erythropoiesisstimulating agents. Clin J Am Soc Nephrol. 2014;9(9):1645-51.

59. Kalantar-Zadeh K. History of erythropoiesis-stimulating agents, the development of biosimilars, and the future of anemia treatment in nephrology. Am J Nephrol. 2017;45(3):235-47.

60. Grabowski H, Guha R, Salgado M. Biosimilar competition: lessons from Europe. Nat Rev Drug Discov. 2014;13(2):99-100.

61. Angst F, Aeschlimann A, Angst J. The minimal clinically important difference raised the significance of outcome effects above the statistical level, with methodological implications for future studies. J Clin Epidemiol. 2017;82:128-36. 